\title{
Isolation and genetic characterization of phenol-utilizing marine bacteria and their phenol degradation pathway
}

\author{
Hiroaki Iwaki, Kengo Takada, Yoshie Hasegawa \\ Department of Life Science \& Biotechnology, Kansai University, 3-3-35 Yamate-Cho, Suita, Osaka 564-8680, Japan
}

Email address:

iwaki@kansai-u.ac.jp (H. Iwaki)

\section{To cite this article:}

Hiroaki Iwaki, Kengo Takada, Yoshie Hasegawa. Isolation and Genetic Characterization of Phenol-Utilizing Marine Bacteria and Their Phenol Degradation Pathway. International Journal of Genetics and Genomics. Vol. 3, No. 2, 2015, pp. 20-25.

doi: $10.11648 /$ j.ijgg.20150302.11

\begin{abstract}
Phenolic compounds are widely distributed toxic pollutants in seawater, and their effective degradation is very important for bioremediation programs. In this study, nine phenol-degrading bacteria were isolated from seawater samples, which were collected from the coastal areas of Japan. Besides the enrichment substrate phenol, all isolates could utilize at least one isomer of cresol as the sole source of carbon. A 16S rRNA gene sequence analysis indicated that all strains were affiliated with the class Gammaproteobacteria, four strains were closely related to Spongiibacter, four were closely related to Marinobacter, and one was closely related to Photobacterium. During growth on phenol, all isolates produced a yellow product, and a whole-cell study indicated that it was an extradiol meta-ring cleavage product of catechol, 2-hydroxymuconate semialdehyde. Phylogenetic analysis revealed that the partial gene encoding the largest subunit of the multicomponent phenol hydroxylase of the isolates was similar to that of terrestrial bacteria, thereby suggesting that phenol is converted into catechol by marine bacteria. We also suggest that horizontal transfer of the gene may occur not only among marine bacteria but also between the genera Marinobacter and Pseudomonas.
\end{abstract}

Keywords: Phenol Degradation, Marine Bacteria, Multicomponent Phenol Hydroxylase, Catechol 2, 3-Dioxygenase, Isolation, Marinobacter, Spongiibacter, Photobacterium

\section{Introduction}

Phenolic compounds are widely distributed toxic pollutants in the environment, which are produced from a variety of industries and natural sources $[1,2]$. Phenolic compounds in the soil flow into rivers because of their high water solubility and rivers flow into the sea; this is the reason for the increase in the concentration of phenolic compounds in the sea. Furthermore, crude oil spills resulting from tanker accidents, submarine and offshore oil field accidents, oil pipeline accidents, etc., also increase the concentration of phenolic compounds in the sea. Therefore, clarifying the mechanism of phenol biodegradation in seawater and assessing the ability to degrade phenol in the marine environment are very important for developing effective bioremediation programs.

A number of phenolic compound-degrading microorganisms have been isolated, and their degradation pathways and genes for degrading phenolic compounds have been studied in detail $[2,3]$. However, these microorganisms have mainly been isolated from terrestrial or freshwater sites. $p$-n-nonylphenol-degrading marine bacteria have been isolated from seawater obtained from coastal areas of Japan; however, these bacteria cannot utilize phenol and cresol as their sole sources of carbon [4, 5]. A phenol-degrading marine bacteria Marinobacter sp. was recently isolated from a harbor in South Africa [6]. However, information regarding phenol-degrading bacteria from marine environments is relatively scarce and there is no information about phenol-degrading genes from marine bacteria. Therefore, more information regarding marine phenol-degrading bacteria and their degradation pathways is required to facilitate the development of effective bioremediation programs. In this paper, we report the isolation of new marine bacteria that utilize phenol as the sole source of carbon, and an analysis of a partial gene from the isolates that encodes the largest subunit of the multicomponent phenol hydroxylase (LmPH). 


\section{Materials and Methods}

\subsection{Isolation of Phenol-Degrading Bacteria from Seawater}

We collected $10 \mathrm{~L}$ of surface seawater from each of five coastal areas of Japan: Chiba, Nagasaki, Okinawa, Fukui, and Ogasawara islands in Tokyo. Marine bacteria were collected from each seawater sample by filtration and resuspended in 30 $\mathrm{mL}$ of commercial artificial seawater medium Daigo's IMK-SP (Nihon Pharmaceutical, Osaka) [7]. Enrichment and purification of the strains were performed according to a previously described procedure with some modifications [7]; Daigo's IMK-SP medium was supplemented with $5 \mathrm{mM}$ phenol.

\subsection{Utilization of Cresols for Growth}

The ability of isolated strains to grow on cresol as the sole source of carbon was determined using Daigo's IMK-SP containing $3 \mathrm{mM} \mathrm{o-}, m$-, or $p$-cresol respectively at $25^{\circ} \mathrm{C}$ for 10 days. Daigo's IMK-SP containing $3 \mathrm{mM}$ phenol was used as a positive control of growth and Daigo's IMK-SP was used as a negative control.

\subsection{Polymerase Chain Reaction and Sequencing Analysis}

16S rRNA gene sequences were determined as previously described [8]. Phylogenetic trees were generated by the neighbor-joining method in MEGA version 6.0 [9]. To amplify the approximately 930-bp long partial gene encoding catechol 2,3-dioxygenase, we used two previously described $\begin{array}{lll}\text { degenerate } & \text { primers } & \text { C23O-ORF-F, }\end{array}$ AGGTGWCGTSATGAAMAAAGG and C23O-ORF-R, TYAGGTSAKMACGTTCAKGAA. To amplify the approximately 620-bp long partial gene encoding LmPH, we used two previously described degenerate primers [11]: pheUf, CCAGGSBGARAARGAGARGAARCT and pheUr, CGGWARCCGCGCCAGAACCA. PCR (Polymerase chain reaction) amplifications were performed using BLEND Taq -Plus- (Toyobo) in a PCR Thermal Cycler Dice (Takara Bio) under the following conditions: 2 min at $94^{\circ} \mathrm{C}$, followed by 30 cycles for $30 \mathrm{~s}$ at $94^{\circ} \mathrm{C}, 30 \mathrm{~s}$ at $55^{\circ} \mathrm{C}$, and $60 \mathrm{~s}$ at $72^{\circ} \mathrm{C}$. DNA sequences of the amplified fragments were determined by directly sequencing with PCR primers. The nucleotide and protein sequence similarity searches were performed using the BLAST program on the NCBI website [12]. Sequence identity values were calculated using GENETYX-MAC version 16 (Genetyx Corporation). The nucleotide sequences determined in this study were deposited in the DNA Data Bank of Japan (DDBJ) under accession numbers AB985579-AB985596 and LC012309.

\subsection{Whole Cell Studies}

The medium used for preparing whole cells was the same as that described above for strain isolation. Cells grown on phenol were harvested in mid-exponential phase by centrifugation at $10,000 \times g$ for $10 \mathrm{~min}$ at $4^{\circ} \mathrm{C}$ and washed twice with $21 \mathrm{mM}$ sodium-potassium phosphate buffer $(\mathrm{pH}$ 7.1) supplemented with $2.0 \% \mathrm{NaCl}$. The cells were resuspended in the buffer to adjust the optical density at 600 $\mathrm{nm}$ to 5.0 , incubated with $2.0 \mathrm{mM}$ phenol in a rotary shaker at $25^{\circ} \mathrm{C}$, and the spent buffer was scanned using a VIS/UV spectrophotometer U-3010 (Hitachi High-Technologies, Tokyo).

\section{Results and Discussion}

Bacterial strains that grew on phenol as the sole source of carbon were isolated from all five sampled areas (Table 1). Besides the enrichment substrate phenol, all strains could utilize $o-, m$-, or $p$-cresol as the sole source of carbon (Table 1) These results indicate that the ability to degrade phenol and cresol is widely spread in the marine environment.

Table 1. Phenol-degrading isolates from seawater

\begin{tabular}{|c|c|c|c|c|c|c|}
\hline \multirow{2}{*}{ Source } & \multirow{2}{*}{ Strain } & \multicolumn{2}{|l|}{ 16S rRNA gene sequence analysis } & \multicolumn{3}{|c|}{ Ability of the isolated strains to grow on: } \\
\hline & & Closest species in database (Acc. No.) & Identity (\%) & $o$-cresol & $m$-cresol & $p$-cresol \\
\hline Chiba & KU17C & Marinobacter litoralis (AF479689) & 100 & + & + & + \\
\hline Nagasaki & KU17D & Spongiibacter marinus (AM117932) & 99.7 & + & - & - \\
\hline Okinawa & KU17E1 & Marinobacter algicola (AY258110) & 98.2 & + & + & + \\
\hline Okinawa & KU17E2 & Photobacterium gaetbulicola (GQ260188) & 96.6 & - & - & + \\
\hline Fukui & KU17F2 & Spongiibacter marinus (AM117932) & 99.9 & + & - & + \\
\hline Fukui & KU17F4 & $\begin{array}{l}\text { Marinobacter hydrocarbonoclasticus } \\
\text { (AB021372) }\end{array}$ & 97.6 & + & + & + \\
\hline Tokyo (Ogasawara islands) & KU17G1 & Spongiibacter marinus (AM117932) & 99.9 & + & - & + \\
\hline Tokyo (Ogasawara islands) & KU17G2 & Spongiibacter marinus (AM117932) & 99.8 & + & - & + \\
\hline Tokyo (Ogasawara islands) & KU17G3 & $\begin{array}{l}\text { Marinobacter hydrocarbonoclasticus } \\
\text { (AB021372) }\end{array}$ & 98.5 & + & + & + \\
\hline
\end{tabular}

The isolated bacteria were characterized by $16 \mathrm{~S}$ rRNA gene sequence analysis (Table 1, Figure 1). We found that all isolates were phylogenetically affiliated with the class Gammaproteobacteria, and the isolates were most closely related to the genera Marinobacter, Spongiibacter, and Photobacterium. For the first time, members of the genera Spongiibacter and Photobacterium were shown to be capable of utilizing phenol. The majority of the isolates were affiliated with Marinobacter and Spongiibacter: four Marinobacter and four Spongiibacter. This observation suggests that members of the genera Marinobacter and Spongiibacter are widely distributed in the sea as phenol degraders. In particular, our finding of Marinobacter is supported by the previous isolation of a phenol-degrading Marinobacter in marine water from 
South Africa [6]. Members of the genus Marinobacter have been reported to be present in a large variety of ecosystems, ranging from extremely cold to hot environments, and they tolerate a broad range of salinity and $\mathrm{pH}$, thereby demonstrating their high adaptive capacity [13]. Furthermore both culture-dependent and -independent methods have indicated that members of the genus Marinobacter are dominant in oil-contaminated marine environments, and these studies have indicated that members of the genus
Marinobacter play an important role in the degradation of several organic compounds in marine environments [14-18]. Together with these reports, our results suggest that members of the genus Marinobacter also play an important role in phenol degradation in several marine environments; thus, they have tremendous potential for applications in the bioremediation of phenol-contaminated marine and saline environments.

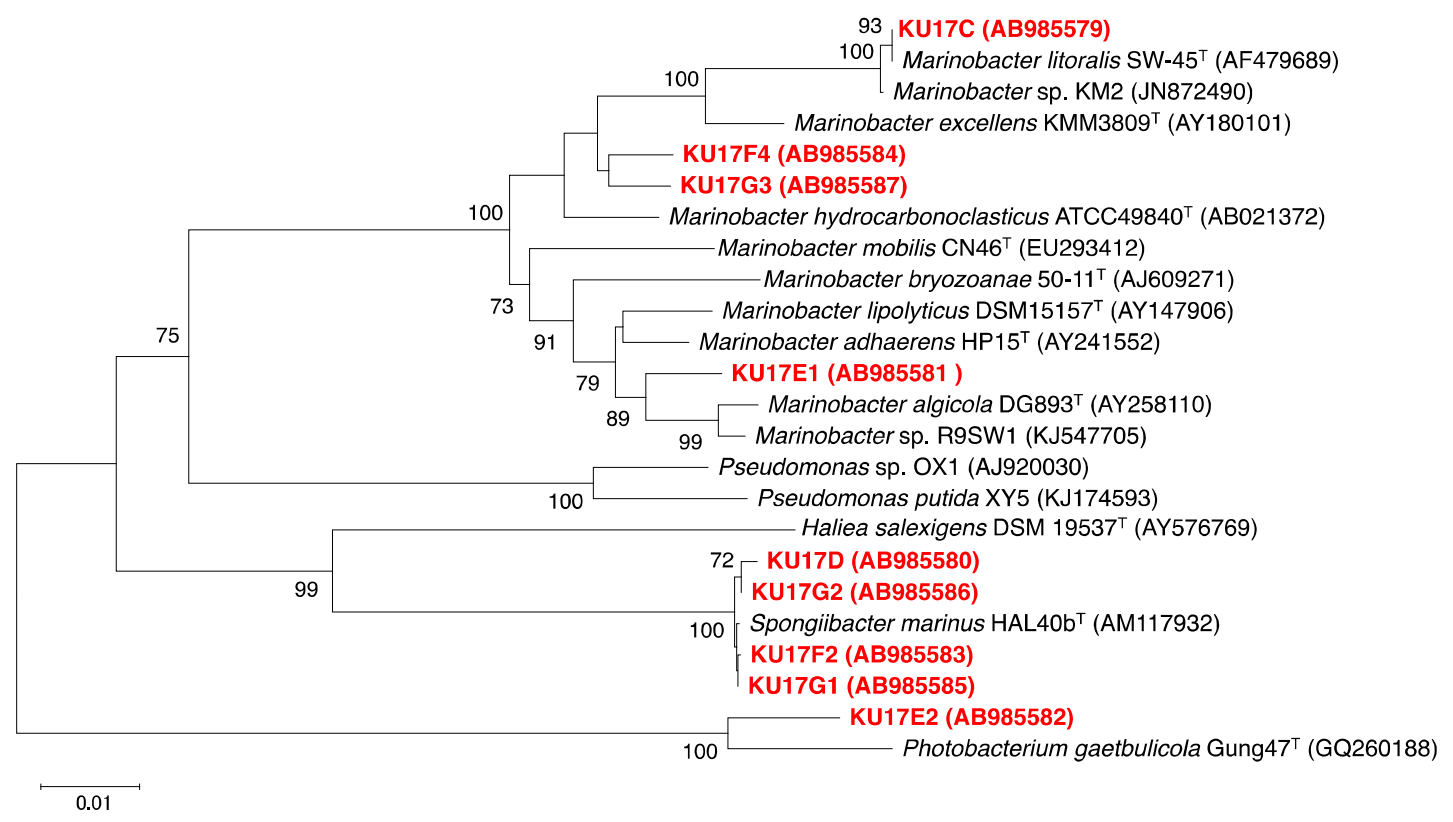

Figure 1. A neighbor-joining tree showing the phylogenetic position of phenol-degrading isolates and their related species based on $16 S$ rRNA gene sequences. The GenBank accession number for each microorganism used in the analysis is shown in parentheses after the species name. Bootstrap values (expressed as a percentage of 1,000 repetitions) $>70 \%$ are shown at the branch. Bar, 0.01 substitutions per nucleotide position.

During growth on phenol, all isolated strains produced a yellow product, which was probably the meta-ring cleavage product 2-hydroxymuconate semialdehyde. To clarify the formation of 2-hydroxymuconate semialdehyde, whole cell studies were performed using the selected strain KU17C. Whole cells of strain KU17C were incubated with phenol and the supernatant was examined using a VIS/UV spectrophotometer (Figure 2). The decrease in absorption at $270 \mathrm{~nm}$ indicated the degradation of phenol and the increase in absorption at $375 \mathrm{~nm}$ indicated the formation of 2-hydroxymuconate semialdehyde, as a result of the extradiol meta-ring cleavage of catechol by catechol 2,3-dioxygenase [19]. A yellow product with maximum absorption at $375 \mathrm{~nm}$ was also produced from catechol by the phenol-grown whole cells of strain KU17C (data not shown). Furthermore, PCR amplification using C23O-ORF primers produced the expected ca 930-bp DNA fragment. The deduced amino acid sequence of the amplified fragment was $78.8 \%$ identical to that of the well-characterized catechol 2,3-dioxygenase of Pseudomonas sp. strain OX1. This high identity strongly suggests that the amplified DNA encodes catechol 2,3-dioxygenase, which supported our finding that catechol is cleaved by meta-cleavage in strain KU17C. The highest score in the BLASTP search was a putative catechol 2,3-dioxygenase from Haliea salexigens strain DSM 19537 with an identity of $98.9 \%$. These results showed that marine phenol-degrading bacteria metabolize phenol via the meta-cleavage pathway, which is catalyzed by two key enzymes: phenol hydroxylase and catechol 2,3-dioxygenase.

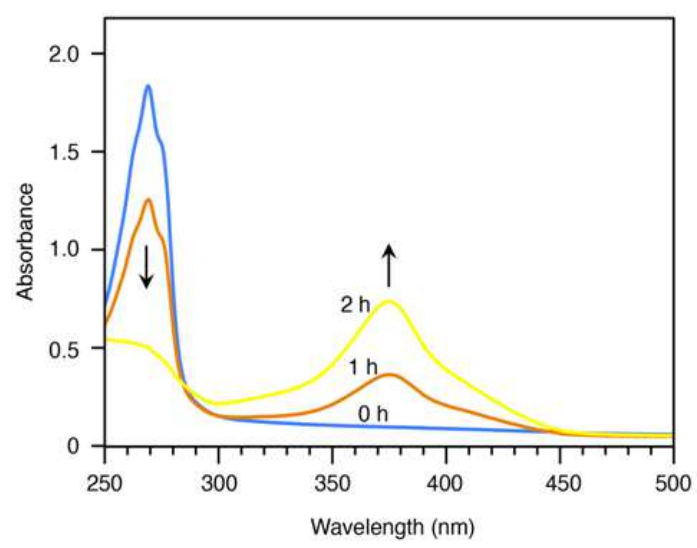

Figure 2. Spectral changes during conversion of phenol by whole cells of strain KU17C grown on phenol. The reaction mixture was scanned at $0 \mathrm{~h}, 1 \mathrm{~h}$, and $2 \mathrm{~h}$. Arrows indicate direction of spectral change.

It has been suggested that multicomponent phenol hydroxylases (mPHs) are dominant in the environment and 
that mPHs among terrestrial bacteria are highly similar [20]. From our conclusion that marine phenol-degrading bacteria metabolize phenol via the same pathway as terrestrial bacteria, and from other reports [20], we hypothesize that marine bacteria also possess genes that encode mPHs. To test this hypothesis, we used PCR to screen for possible genes encoding LmPH in the genomic DNA of isolates, and then performed a phylogenetic analysis of these genes (Figure 3 ). As expected, an approximately 600-bp DNA fragment was amplified from the genomic DNA of all the isolates (data not shown). The nucleotide sequence and the deduced amino acid sequences of the amplified fragments were $75.1 \%-88.0 \%$ and $79.8 \%-96.7 \%$ identical to the $\mathrm{LmPH}$ of the well-characterized mPH of Pseudomonas sp. strain OX1 (Table 2) [21-25], respectively. These high identities strongly suggest that the amplified DNA sequences encode LmPH. Among the isolates, the deduced amino acid sequence identities of the amplified fragments ranged from $79.8 \%-100 \%$. These high similarities suggest that the genes encoding $\mathrm{LmPH}$ in these isolates and in Pseudomonas sp. strain OX1 were derived from the same origin, but varied over a long time, and thus phenol utilization by the marine isolates and terrestrial bacteria involves a common mechanism.

Table 2. Identities of the nucleotide sequence and the deduced amino acid sequence of putative LmPH genes from isolates compared with those of LmPH genes from Pseudomonas sp. strain $\mathrm{OXI}$

\begin{tabular}{lll}
\hline Strain & $\begin{array}{l}\text { Nucleotide sequence } \\
\text { identity (\%) }\end{array}$ & $\begin{array}{l}\text { Amino acid sequence } \\
\text { identity (\%) }\end{array}$ \\
\hline KU17C & 85.8 & 93.4 \\
KU17D & 80.8 & 95.6 \\
KU17E1 & 84.9 & 94.5 \\
KU17E2 & 75.1 & 79.8 \\
KU17F2 & 80.6 & 95.6 \\
KU17F4 & 87.7 & 95.1 \\
KU17G1 & 80.9 & 95.6 \\
KU17G2 & 81.9 & 95.6 \\
KU17G3 & 88.0 & 96.7 \\
\hline
\end{tabular}

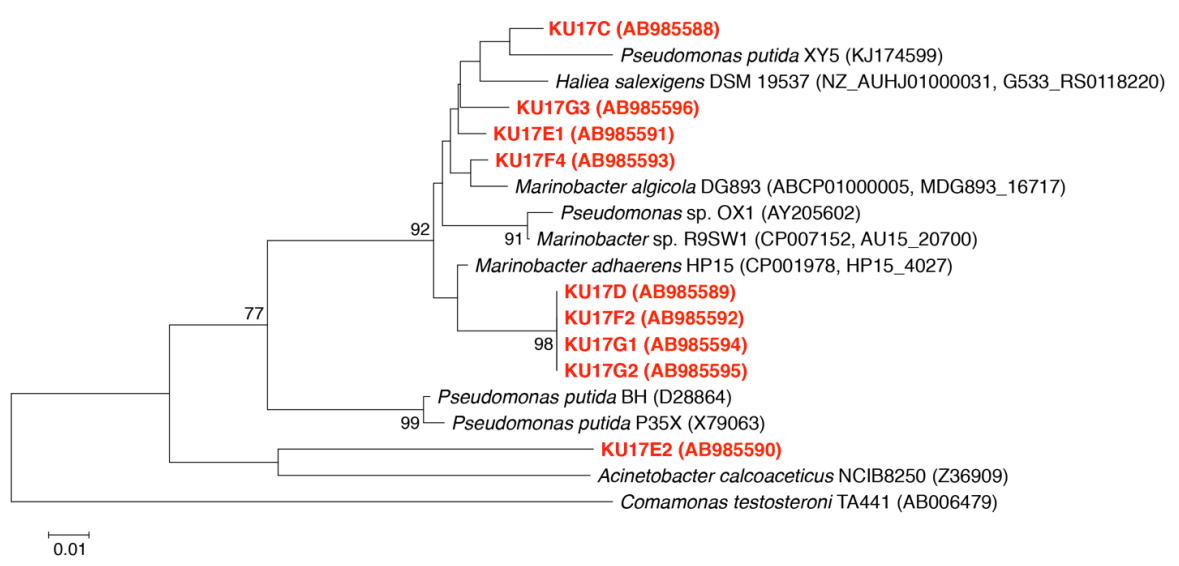

Figure 3. Neighbor-joining tree showing the phylogenetic position of the nucleotide sequence of genes encoding the putative partial LmPH. The GenBank accession number for each gene is shown in parentheses after the species name. Bootstrap values (expressed as a percentage of 1,000 repetitions) $>70 \%$ are shown at the branch. Bar, 0.01 substitutions per nucleotide position.

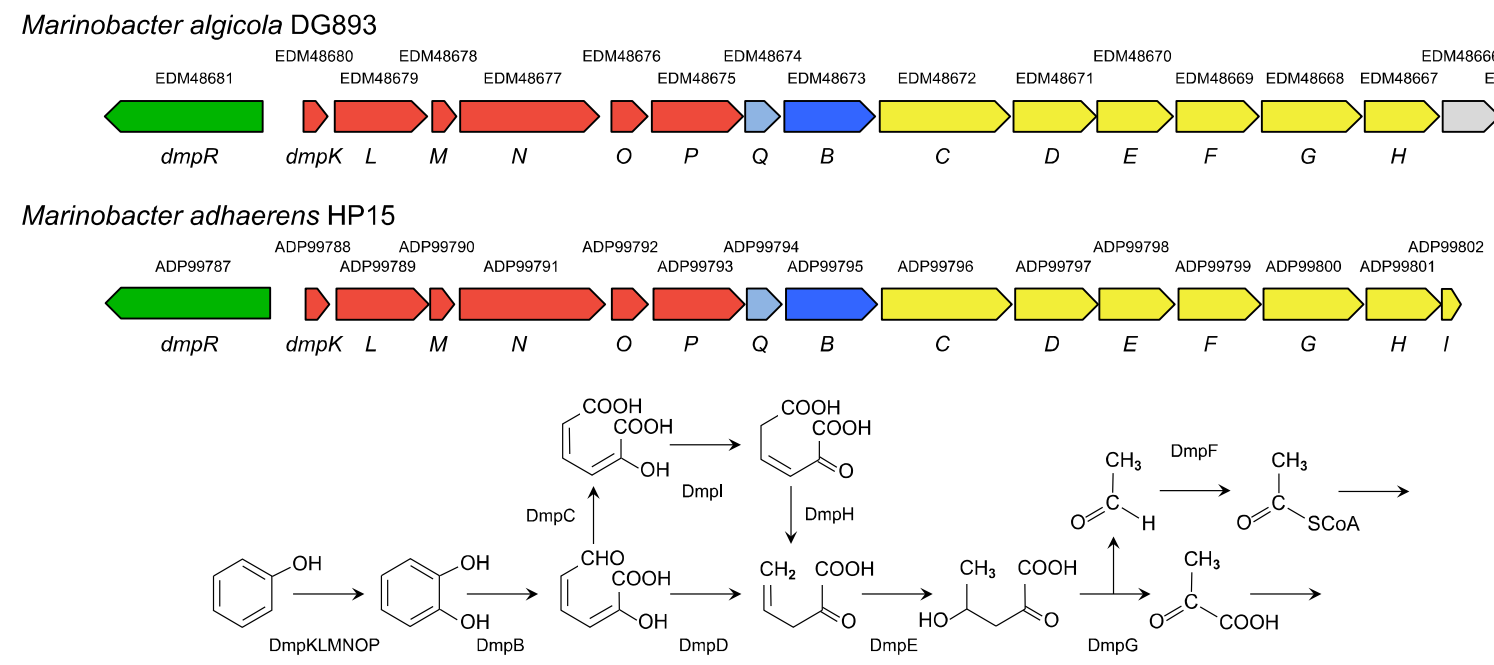

Figure 4. Organization of putative phenol degradation gene clusters in the genome sequences of Marinobacter algicola strain DG893 and Marinobacter adhaerens strain HP15, and proposed phenol degradation pathway. DmpR, NtrC family transcriptional activator; DmpKLMNOP, components of phenol hydroxylase; DmpB, catechol 2,3-dioxygenase; DmpC, 2-hydroxymuconic semialdehyde dehydrogenase; DmpD, 2-hydroxymuconic semialdehyde hydrolase, DmpE, 2-oxopent-4-dienoate hydratase; DmpF, acetaldehyde dehydrogenase; DmpG, 4-hydroxy-2-oxovalerate aldolase; DmpH, 4-oxalocrotonate decarboxylase; DmpI, 4-oxalocrotonate isomerase; and DmpQ, ferredoxin-like protein involved in reactivation of catechol 2,3-dioxygenase. 
BLASTP searches revealed that two Marinobacter genomes, i.e., those of Marinobacter algicola strain DG893 (accession number: ABCP01000005) and Marinobacter adhaerens strain HP15 (accession number: CP001978) contain a gene encoding a putative $\mathrm{LmPH}$, and the remaining phenol meta-cleavage pathway genes are located in the DNA region adjacent of the gene (Figure 4) [26, 27]. This supports our finding that Marinobacter spp. degrade phenol via the meta-cleavage pathway. BLASTP searches also showed that the deduced amino acid sequence of the LmPH amplified from strain KU17C exhibited the highest score when compared with the deduced amino acid sequence of the putative LmPH gene of Haliea salexigens strain DSM 19537, with amino acid sequence identity of $97.8 \%$ and nucleotide sequence identity of $91.3 \%$. Although protein-encoding genes have been reported to vary much faster than rRNA-encoding genes [28], the divergence in the 16S rRNA gene sequences of strain KU17C and Haliea salexigens strain DSM 19537 $(12.8 \%)$ was higher than the divergence in their LmPH gene sequences $(8.7 \%)$. Similarly, the putative LmPH gene of the terrestrial Pseudomonas putida strain XY5 was only $2.4 \%$ divergent with strain $\mathrm{KU} 17 \mathrm{C}$, and the putative $\mathrm{LmPH}$ gene of Marinobacter sp. strain R9SW1 was only $4.5 \%$ divergent with the LmPH gene of Pseudomonas sp. strain OX1. The divergence rates in the $16 \mathrm{~S}$ rRNA gene sequences were $10.6 \%$ and $10.2 \%$, respectively. These results suggest that $\mathrm{LmPH}$ genes were horizontally transferred among these bacterial lineages. The horizontal transfer of an aromatic compound-degrading gene between the genera Marinobacter and Pseudomonas has also been suggested for the naphthalene-degrading Marinobacter sp. strain NCE312 [29].

\section{Conclusion}

In this study, we successfully isolated nine phenol-utilizing marine bacteria, which were most closely related to the genera Marinobacter, Spongiibacter, and Photobacterium. PCR screening revealed that all isolates possessed a gene that encoded putative $\mathrm{LmPH}$, which was similar to that found in terrestrial bacteria. The sequence data for $\mathrm{LmPH}$-encoding genes analyzed in this study should facilitate the development of informative genetic markers to evaluate the efficacy of bioremediation in phenol-contaminated marine and saline environments. Further genetic analysis will provide more useful information to support the development of the genetic markers and the improvement of the phenol biodegradation potential of the isolated strains, which may contribute to phenol bioremediation processes in various saline ecosystems, although these studies are outside our present scope.

\section{References}

[1] Michałowicz J, Duda W (2007) Phenols - Sources and Toxicity Polish Environ Stud 16:347-362

[2] vanSchie PM, Young LY (2000) Biodegradation of phenol: mechanisms and applications. Bioremed J 4:1-18

[3] Nair CI, Jayachandran K, Shashidhar S (2008) Biodegradation of phenol. African J Biotechnol 7:4951-4958

[4] Iwaki H, Fujioka M, Hasegawa Y (2014) Isolation and characterization of marine nonylphenol-degrading bacteria and description of Pseudomaricurvus alkylphenolicus gen. nov., sp. nov. Curr Microbiol 68:167-173

[5] Iwaki H, Takada K, Hasegawa Y (2012) Maricurvus nonylphenolicus gen. nov., sp. nov., a nonylphenol - degrading bacterium isolated from seawater. FEMS Microbiol Lett 327:142-147

[6] Moxley K, Schmidt S (2012). Isolation of a phenol-utilizing marine bacterium from Durban Harbour (South Africa) and its preliminary characterization as Marinobacter sp. KM2. Water Sci Technol 65:932-939

[7] Iwaki H, Nishimura A, Hasegawa Y (2012) Isolation and characterization of marine bacteria capable of utilizing phthalate. World J Microbiol Biotechnol 28:1321-1325

[8] Iwaki H, Hasegawa Y, Wang S, Kayser MM, Lau PC (2002) Cloning and characterization of a gene cluster involved in cyclopentanol metabolism in Comamonas sp. strain NCIMB 9872 and biotransformations effected by Escherichia coli-expressed cyclopentanone 1,2-monooxygenase. Appl Environ Microbiol 68:5671-5684

[9] Tamura K, Stecher G, Peterson D, Filipski A, Kumar S (2013) MEGA6: Molecular Evolutionary Genetics Analysis Version 6.0. Mol Biol Evol 30:2725-2729

[10] Junca H, Pieper DH (2003) Amplified functional DNA restriction analysis to determine catechol 2,3-dioxygenase gene diversity in soil bacteria. J Microbiol Meth 55:697-708

[11] Futamata H, Harayama S, Watanabe K (2001) Group-specific monitoring of phenol hydroxylase genes for a functional assessment of phenol-stimulated trichloroethylene bioremediation. Appl Environ Microbiol 67:4671-4677

[12] Altschul SF, Madden TL, Schäffer AA, Zhang J, Zhang Z, Miller W, Lipman DJ (1997) Gapped BLAST and PSI-BLAST: a new generation of protein database search programs. Nucleic Acids Res 25:3389-3402

[13] Duran R (2010) Marinobacter, in Handbook of Hydrocarbon and Lipid Microbiology, ed K. N. Timmis (Berlin, Heidelberg: Springer-Verlag), 1725-1735

[14] Hernandez-Raquet G, Budzinski H, Caumette P, Dabert P, Le Ménach K, Muyzer G, Duran R (2006) Molecular diversity studies of bacterial communities of oil polluted microbial mats from the Etang de Berre (France). FEMS Microbiol Ecol 58:550-562

[15] Kostka JE, Prakash O, Overholt WA, Green SJ, Freyer G, Canion A, Delgardio J, Norton N, Hazen TC, Huettel M (2011) Hydrocarbon-degrading bacteria and the bacterial community response in Gulf of Mexico beach sands impacted by the Deepwater Horizon oil spill. Appl Environ Microbiol 77:7962-7974

[16] Nicholson CA, Fathepure BZ (2004) Biodegradation of benzene by halophilic and halotolerant bacteria under aerobic conditions. Appl Environ Microbiol 70:1222-1225 
[17] Yakimov MM, Denaro R, Genovese M, Cappello S, D'Auria G, Chernikova TN, Timmis KN, Golyshin PN, Giluliano L (2005) Natural microbial diversity in superficial sediments of Milazzo Harbor (Sicily) and community successions during microcosm enrichment with various hydrocarbons. Environ Microbiol 7:1426-1441

[18] Zhao C, Ruan L (2011) Biodegradation of Enteromorpha prolifera by mangrove degrading micro-community with physical-chemical pretreatment. Appl Microbiol Biotechnol 92:709-716

[19] Kojima Y, Itada N, Hayaishi O (1961) Metapyrocatachase: a new catechol-cleaving enzyme. J Biol Chem 236:2223-2228

[20] Watanabe K, Teramoto M, Futamata H, Harayama S (1998) Molecular detection, isolation, and physiological characterization of functionally dominant phenol-degrading bacteria in activated sludge. Appl Environ Microbiol 64:4396-4402

[21] Cafaro V, Izzo V, Scognamiglio R, Notomista E, Capasso P, Casbarra A, Pucci P, DiDonato A (2004) Phenol hydroxylase and toluene/o-xylene monooxygenase from Pseudomonas stutzeri OX1: interplay between two enzymes. Appl Environ Microbiol 70:2211-2219

[22] Izzo V, Leo G, Scognamiglio R, Troncone L, Birolo L, DiDonato A (2011) PHK from phenol hydroxylase of Pseudomonas sp. OX1. Insight into the role of an accessory protein in bacterial multicomponent monooxygenases. Arch Biochem Biophys 505:48-59

[23] McCormick MS, Lippard SJ (2011) Analysis of substrate access to active sites in bacterial multicomponent monooxygenase hydroxylases: X-ray crystal structure of xenon-pressurized phenol hydroxylase from Pseudomonas sp. OX1. Biochemistry 50:11058-11069

[24] Sazinsky MH, Dunten PW, McCormick MS, DiDonato A, Lippard SJ (2006) X-ray structure of a hydroxylase-regulatory protein complex from a hydrocarbon-oxidizing multicomponent monooxygenase, Pseudomonas sp. OX1 phenol hydroxylase. Biochemistry 45:15392-15404

[25] Tinberg CE, Song WJ, Izzo V, Lippard SJ (2011) Multiple roles of component proteins in bacterial multicomponent monooxygenases: phenol hydroxylase and toluene/o-xylene monooxygenase from Pseudomonas sp. OX1. Biochemistry 50:1788-1798

[26] Shingler V, Powlowski J, Marklund U (1992) Nucleotide sequence and functional analysis of the complete phenol/3,4-dimethylphenol catabolic pathway of Pseudomonas sp. strain CF600. J Bacteriol 174:711-724

[27] Hugo N, Meyer C, Armengaud J, Gaillard J, Timmis KN, Jouanneau Y (2000) Characterization of three XylT-like [2Fe-2S] ferredoxins associated with catabolism of cresols or naphthalene: evidence for their involvement in catechol dioxygenase reactivation. J Bacteriol 182:5580-5585

[28] Ochman H,Wilson AC (1987) Evolution in bacteria: evidence for a universal substitution rate in cellular genomes. J Mol Evol 26:74-86

[29] Hedlund BP, Geiselbrecht AD, Staley JT (2001) Marinobacter strain NCE312 has a Pseudomonas-like naphthalene dioxygenase. FEMS Microbiol lett 201:47-51 